\title{
Retinal Development and Opsin Gene Expression during the Juvenile Development in Red Spotted Grouper (Epinephelus akaara)
}

\author{
Eun-Su Kim¹, Chi-Hoon Lee ${ }^{1,2}$, and ${ }^{\dagger}$ Young-Don Lee ${ }^{1}$ \\ ${ }^{1}$ Marine Science Institute, Jeju National University, Jeju 63333, Korea \\ ${ }^{2}$ CR Co., Ltd. Jeju 63333, Korea
}

\begin{abstract}
To produce healthy and stable seed production, we need to obtain information and understand vision that affects behavior of red spotted grouper. We examined their expression and retinal development during the juvenile development. Short-wavelength sensitive opsin (SWS2), a cone photoreceptor, began to be expressed from lens and ear vesicle formation stage and its expression increased until 10 days after hatching (dah). In case of middle-wavelength sensitive opsin (MWS), its expression was detected at 3 dah and reached the highest level at 21 dah. The expression of long-wavelength sensitive opsin (LWS) was first observed from 3 dah and their expression decreased thereafter. Rhodopsin, a rod photoreceptor, was found to be expressed from 2 dah and its expression reached the highest level at 50 dah. The outer nuclear layer (ONL), inner nuclear layer (INL) and ganglion cell layer began to differentiate at 2 dah, while choroid first appeared at 4 dah so that the eyes became black. These results indicate that the development of retina mostly completes around 4 dah. It seems that the development of the retina and the expression of the opsin genes are closely related to the behavior such as hunting prey, considering that the timing of the completion of the development of the retina, the timing of gene expression, and the timing of completion of yolk absorption are similar.
\end{abstract}

Key words : Red spotted grouper, Retina, Opsin, Cone photoreceptor, Rod photoreceptor

\section{INTRODUCTION}

In feeding and management in fish farming, light, water temperature, and food are important external environmental variables. In particular, light is a major external environmental factor that influences all aspects of life of fish, including embryonic development and puberty (Villamizar et al., 2011). The visual system in which information of light is obtained through the retina is an important sense in finding foods and directions as well as in recognizing predators (Rodriguez \& Gisbert, 2001). The retina of fish consists of an epithelial layer and multiple neuronal layers. In particular, it consists of the pigment epithelium (PE), the rods and cones layer (PR) with photoreceptors, the outer nuclear layer (ONL) containing the nuclei of photoreceptors, the outer plexiform layer (OPL) where photoreceptors, bipolar cells, and horizontal cells took synaptic combination, the inner nuclear layer (INL) containing bipolar cells, horizontal cells, and amacrine cells, the inner plexiform layer (IPL) where bipolar cells and amacrine cells took synaptic combination to ganglion cells, and the ganglion cell layer (GCL). Visual information entering the

Manuscript received May 7, 2019, Received in revised form May 21, 2019, Accepted May 30, 2019

${ }^{\dagger}$ Corresponding Author : Young-Don Lee, Marine Science Institute, Jeju National University, Jeju 63333, Korea. Tel: +82-64-782-8922, Fax: +82-64-828281, E-mail: leemri@jejunu.ac.kr; leesisu@hanmail.net

This is an Open Access article distributed under the terms of the Creative Commons Attribution Non-Commercial License (http:// creative-commons.org/licenses/by-nc/3.0) which permits unrestricted non-commercial use, distribution, and reproduction in any medium, provided the original work is properly cited. 
photoreceptors pass through bipolar cells and ganglion cells, after which they pass through the optic nerve to reach the optic lobe (Stenkamp, 2015).

Photoreceptors are membrane receptors that receive light, which gets transferred to the brain through the nervous system to form images in the brain. Photoreceptors of most Osteichthyes consist of rods and cones; rods recognize the bright and dark of light while different subtypes of cones recognize different light wavelengths. Among these different cone subtypes, short-wavelength sensitive opsin (SWS2) recognizes short wavelengths, middle-wavelength sensitive opsin (MWS) recognizes medium wavelengths, whereas long-wavelength sensitive opsin (LWS) recognizes long wavelengths (Carleton, 2009). Moreover, photoreceptors in fish play important roles in feeding, growth, and development of larvae, in addition to vision (Boeuf \& Le Bail, 1999; Villamizar et al., 2011). Research on retinal development are being conducted in various fish species, including herring (Sandy \& Blaxter, 1980), deep sea luminous fish (Bozzano et al., 2007), and dark banded rockfish (Park et al., 2012).

Red spotted grouper (Epinephelus akaara), which belong to the order Perciformes and the family Serranidae. Epinephelus genus comprise 15 genera and 159 species, including longtooth grouper (E. bruneus), red spotted grouper (E. akaara), and sevenband grouper (E. septemfasciatus), and they mostly live in eastern Atlantic Ocean and Mediterranean Sea. Red spotted grouper, which are sedentary fish, mostly inhabit rocky zones of the coast; they are also nocturnal carnivores preying on crustaceans and fish (Kim et al., 2001). Red spotted grouper is a fish species that requires monitoring due to rapidly decreasing coastal resources. Moreover, since there is a very high market demand for them, they are very expensive, and continued investments are being made to promote farming (Sadovy, 2001).

The difficulty in rearing most grouper species including red spotted grouper is a high mortality in the larval stage around the time of mouth opening. Therefore, in order to improve this, many studies have investigated ways to improve initial survival rates, including changes in illumination of the farming tank, formation of oil films, and formation of water currents through bubbles (Yamaoka et al., 2000; Sakakura et al., 2006; Yoseda et al., 2008). The applied lighting for larval rearing tanks should be based on the visual system of the target species being reared. $\mathrm{Nu}$ merous studies have investigated the visual system according to retinomotor responses, visual sensitivity, light intensity requirements for feeding behaviour of grouper larvae (Ellis et al., 1997; Toledo et al., 2002; Mukai et al., 2012), but there have been no such investigations on red spotted grouper.

In order to obtain information on the visual system in red spotted grouper larvae, which influences their behavior, and to understand the behaviors of the larvae, we investigated the differentiation and development of the epithelial and neuronal layers of their retina and opsin gene expression patterns in photoreceptors in different growth stages through gene cloning.

\section{MATERIALS AND METHODS}

\section{Experimental fish}

Red spotted grouper larvae seed-produced at the Marine Science Institute of Jeju National University was used as the experimental fish. In order to induce ovulation and spermiation in red spotted grouper, mature female and male groupers were selected, and human chorionic gonadotropin (HCG) was injected through cannulation in doses of 500 IU per kg body weight. To produce fertilized eggs, eggs and semen were obtained through abdominal compression 48 hours later after hormone injection and were fertilized artificially through wet processes.

\section{Retinal development according to growth stages}

1) Larvae management 
For larvae farming, fertilized eggs floating in upper layers were collected and placed into a 12-ton farming tank. Throughout farming, the water temperature was maintained within $24 \pm 1^{\circ} \mathrm{C}$, DO at 7.0-8.0, and $\mathrm{pH}$ at 7.0-8.0. In terms of the food provided to the larvae after hatching, Branchionus rotundiformis was provided between 3 days after hatching (dah; when larvae opened their mouth) and 35 dah, and Artemia nauplii was provided starting on 20 dah. All experiments were conducted in compliance with both the Animal Care and Use Committee guidelines of the Jeju National University.

\section{2) Morphological development and behavioral cha-} racteristics of red spotted grouper larvae

In order to investigate morphological development and behavioral characteristics, more than three red spotted grouper larvae were observed and filmed using a stereoscopic microscope (2000-C, ZEISS) at each time point. Investigations were conducted at the following points: lens and ear vesicle formation (fertilized egg), 1 day after hatching (dah), 2 dah, 3 dah with completion of yolk absorption, 5 dah, 10 dah, 21 dah after spine formation, and 50 dah after the completion of metamorphosis.

\section{3) Retinal development}

In investigating retinal development and opsin gene expression patterns in red spotted grouper larvae, sampling was conducted at the same time points as the investigation time of morphological development and behavioral characteristics of red spotted grouper. For histological analysis, samples were fixed in Bouin's solution. The fixed tissues were dehydrated using ethanol by different concentrations and embedded in paraffin. The paraffin block was sliced at $5 \mu \mathrm{m}$, and the sliced tissue samples were stained in hematoxylin and $0.5 \%$ eosin (HE) and observed using an optical microscope (BX53, Olympus) and an imaging software (Olympus cellSens ${ }^{\text {TM }}$ Microscope Imaging Software).

\section{Opsin gene expression patterns}

\section{1) Partial cloning of opsin genes}

Partial cloning was conducted to compare opsin gene expression patterns at different growth stages. Using the information reported on the National Center for Biotechnology Information (NCBI) website, the factors of shortwavelength sensitive opsin (SWS2), middle-wavelength sensitive opsin (MWS), long-wavelength sensitive opsin (LWS), and rod opsin genes were selected and cloned through TA cloning. Degenerate primers were produced using opsin gene information in related fish species, including those belonging to Perciformes, obtained through NCBI (Table 1). The genes were amplified through PCR and inserted into a T-Blunt ${ }^{\mathrm{TM}}$ PCR Cloning Kit (SolGent), then followed by ligation. Partial DNA sequences of opsin genes were analyzed by Genotech (Korea) once we separated plasmid DNA after transformation. Partial sequences of opsin genes were confirmed through NCBI Blast. Cloned genes were investigated in phylogenic analyses conducted on MEGA7.

\section{2) Total RNA extraction and cDNA synthesis}

Tissue samples were obtained from red spotted grouper to investigate opsin gene expression by tissues in comparison to hatched larvae. The samples were mixed with 600 $\mu \mathrm{L}$ of RiboEx ${ }^{\mathrm{TM}} \mathrm{LS}$ (GeneAll, Korea) to be crushed. The $20 \mu \mathrm{L}$ of chloroform was added to every $100 \mu \mathrm{L}$ of Ribo$\mathrm{Ex}^{\mathrm{TM}} \mathrm{LS}$, and the samples were then centrifuged for 15 minutes at $4^{\circ} \mathrm{C}$ and $12,000 \mathrm{~g}$ to isolate the supernatant. Isopropanol was added to the supernatant isolated from the first centrifugation, and the supernatant was centrifuged again to precipitate RNA. After the second centrifugation, the supernatant was discarded, and the samples were washed in $75 \%$ ethanol containing diethyl pyrocarbonate (DEPC). The precipitated RNA was dissolved in RNasefree distilled water. The concentration of extracted total RNA was measured using Nano Vue (GE Healthcare, UK), 
and the samples used showed the range between 1.7 and 2.1 in ratio of A260/A280 nm. After the samples were treated with DNase using a RQ1 RNase-Free DNase Kit (Promega, USA), cDNA was synthesized using Prime Script $^{\mathrm{TM}}$ 1st strand cDNA synthesis Kit (Takara, Japan). RNase-free $\mathrm{H}_{2} \mathrm{O}$ was added to DNase-treated total RNA to make a final volume of $8 \mu \mathrm{L}$. Random 6 mers $1 \mu \mathrm{L}$ and dNTP mixture $1 \mu \mathrm{L}$ were then added, and the mixture was reacted for 5 minutes at $65^{\circ} \mathrm{C}$. $5 \mathrm{X}$ PrimeScript Buffer $4 \mu \mathrm{L}$, RNase Inhibitor $0.5 \mu \mathrm{L}$, PrimeScript RTase $1 \mu \mathrm{L}$, and RNase free $\mathrm{dH}_{2} \mathrm{O} 4.5 \mu \mathrm{L}$ were mixed into $10 \mu \mathrm{L}$ of the reacted mixture. After further reactions were induced for 10 minutes at $30^{\circ} \mathrm{C}$ and for 60 minutes at $42^{\circ} \mathrm{C}$, and cDNA was synthesized through 5 minutes of enzymatic activity at $95^{\circ} \mathrm{C}$. The synthesized cDNA was used to partially clone opsin genes in red spotted grouper using primers constructed by referencing the sequences of opsin genes registered on NCBI. The primers were produced based on the sequences of cloned opsin genes in red spotted grouper and were used for RT-PCR and real-time quantitative PCR analyses to analyze the expression of opsin genes in each tissue (Table 1).

\section{3) Real-time quantitative PCR}

In order to compare expression patterns of opsin genes by growth stages, sampling was conducted at lens and ear vesicle formation (fertilized egg), 1 dah (day after hatching), 2 dah, 3 dah with completion of yolk absorption, 5 dah, 10 dah, 21 dah with spine formation, and 50 dah with the completion of metamorphosis. The extracted samples were stored at $-80^{\circ} \mathrm{C}$ until analysis. BioRad CFX96 ${ }^{\mathrm{TM}}$ Touch $^{\text {TM }}$ Real Time PCR (BioRad, Hercules, CA) was used for quantitative analysis. Using the synthesized cDNA as the template, EvaGreen 2X qPCR MasterMix (abm, Canada) $5 \mu \mathrm{L}$, forward primers $0.3 \mu \mathrm{L}(10 \mathrm{uM})$ and reverse primers $0.3 \mu \mathrm{L}(10 \mathrm{uM})$, and RNase free $\mathrm{H}_{2} \mathrm{O} 2.4 \mu \mathrm{L}$ were mixed together to make a total volume of $10 \mu \mathrm{L}$. The mixture was then amplified in 40 cycles of denaturation (45 s, $\left.94^{\circ} \mathrm{C}\right)$, annealing $\left(45 \mathrm{~s}, 58^{\circ} \mathrm{C}\right)$, and extension $\left(1 \mathrm{~m}, 72^{\circ} \mathrm{C}\right)$ and relatively quantified using $\beta$-actin as a control; the mean values were used in analysis.

\section{Statistical analysis}

Gene expression pattern results were tested in one-way analysis of variance (ANOVA), and the significance was tested in Duncan's multiple range test.

\section{RESULTS}

\section{Morphological development}

Morphological characteristics of hatched larvae were investigated using a stereoscopic microscope according to growth stages. One day after hatching, the yolk comprised most of the body, and a digestive tract connected to the anus within the abdominal cavity was observed at 2 dah. At 3 dah yolk absorption was complete in larvae, and the eyes started turning black. Moreover, before 4 dah, the larvae could not swim and instead floated around the water flow created by bubbles. Around 4 dah, the mouth had opened, and the internal diameter of the digestive tract increased. Further, with swimming abilities, the larvae tended to descend from the surface of the water. Around 10 dah, red spotted grouper larvae had protrusion of the second spine of the dorsal fin and spines of the pectoral fin and tended to group together. At 21 dah, spines of dorsal and pectoral fins spread to the caudal fin, and groups of larvae swam. At 50 dah, metamorphosis was complete in larvae, and the larvae were now in similar appearance as adult red spotted grouper (Fig. 1). Regarding pigmentation of the retina of red spotted grouper, chromatophores were observed starting at 27 hours after hatching at a water temperature of $21^{\circ} \mathrm{C}$. Groupers with black pigmentation starting from the edges of the eyes were observed starting at 46 hours after hatching, and those with complete pigmentation were also observed (Fig. 2). 
Table 1. Primer sets used in RT-PCR an real-time quantitative PCR

\begin{tabular}{|c|c|c|}
\hline Primer sets & Genes & Sequence(5'-3') \\
\hline \multirow{10}{*}{ RT-PCR } & SWS2-F & CATGCACCATCCAGAACAAG \\
\hline & SWS2-R & CACAGCAAAGCAGAATCCAA \\
\hline & MWS-F & CCAACAGGACTGGGATTGTT \\
\hline & MWS-R & AAGCCTGGAGCCAGAGTGTA \\
\hline & LWS-F & TGCAATTGCTGATCTTGGAG \\
\hline & LWS-R & CATGACAACGACCATTCTGG \\
\hline & Rod-F & CTGCGGACCCCTCTAAACTA \\
\hline & Rod-R & GTGAGGAAGTGGCATGTGAA \\
\hline & $\beta$-actin-F & GAGCGTGGCTACTCCTTCAC \\
\hline & $\beta$-actin-R & AGGAAGGAAGGCTGGAAGAG \\
\hline \multirow{10}{*}{ Real-time qPCR } & SWS2-F & CGGTCCCACCTCAACTACAT \\
\hline & SWS2-R & GGTCAGGCTTGAAAGCAAAG \\
\hline & MWS-F & TGGAGGTGAAGTCGCTCTCT \\
\hline & MWS-R & AAGCCTGGAGCCAGAGTGTA \\
\hline & LWS-F & GTGTGGTGTTCTCCGCCTAT \\
\hline & LWS-R & CATGACAACGACCATTCTGG \\
\hline & Rod-F & CCCTCTGGTCACTGGTTGTT \\
\hline & Rod-R & TCATGAAGTGGCAGCAGAAC \\
\hline & $\beta$-actin-F & GAGCGTGGCTACTCCTTCAC \\
\hline & $\beta$-actin-R & AGGAAGGAAGGCTGGAAGAG \\
\hline
\end{tabular}

2. Retinal structure and development

Hatched larvae had ONL, INL, and GCL starting from 2 dah, and the choroid membrane formed starting from 4 dah. When retinal layers were compared, the degree of differentiation in all layers were similar between the day 4 after hatching and 12 months after hatching. However, the thickness of each layer varied by growth stages (Fig. 3). Moreover, regarding the thickness of retinal layers by growth stage, the overall retinal thickness tended to increase gradually with growth of the larvae, and the thick- ness of each layer also increased overall. The GCL thickness decreased starting from 50 dah (Table 2).

\section{Expression of opsin genes in tissues}

To investigate the expression of cloned opsin genes in tissues, forebrain, midbrain, hindbrain, eyes, pituitary gland, tongue, liver, spleen, kidneys, heart, intestines, muscles (including the lateral line), gonads, and gills were extracted from adult red grouper for analysis (Table 3). Most opsin genes were strongly expressed in the eyes (Fig. 4). 


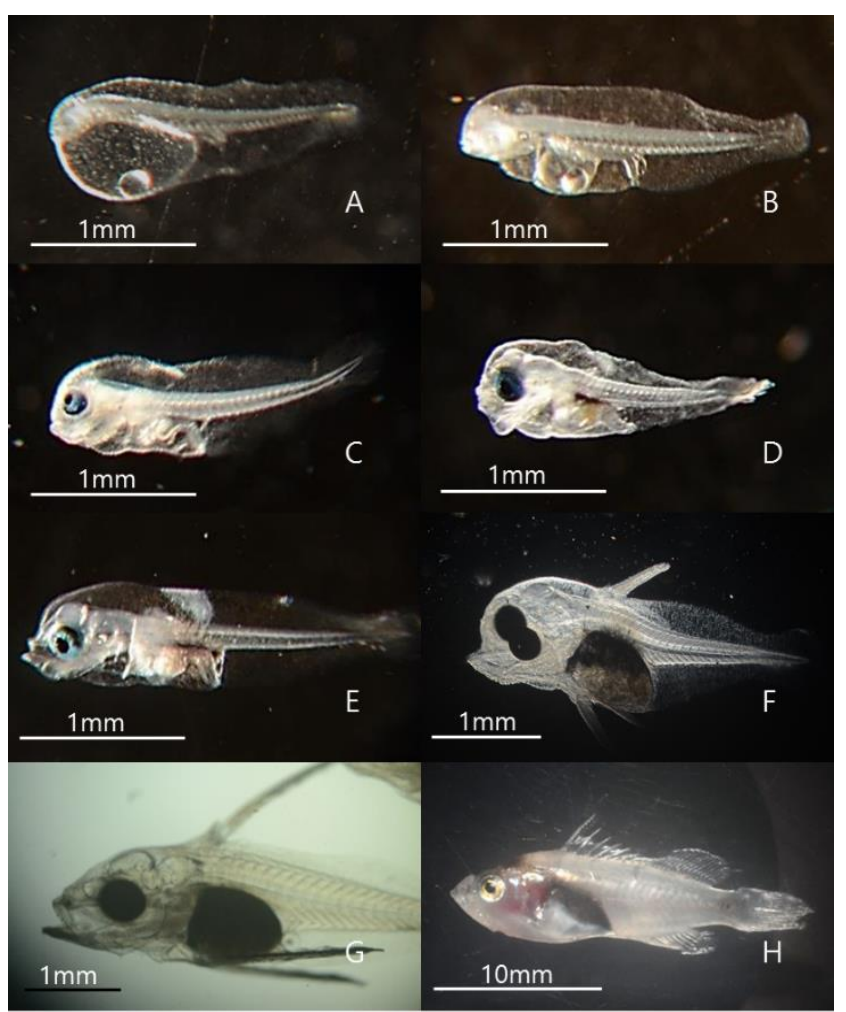

Fig. 1. Photographs of each growth stage red spotted grouper. A, 1 dah; B, 2 dah; C, 3 dah; D, 4 dah; E, 5 dah; F, 10 dah; G, 21 dah, H, 50 dah (Postmetamorphosis). dah, days after hatching.

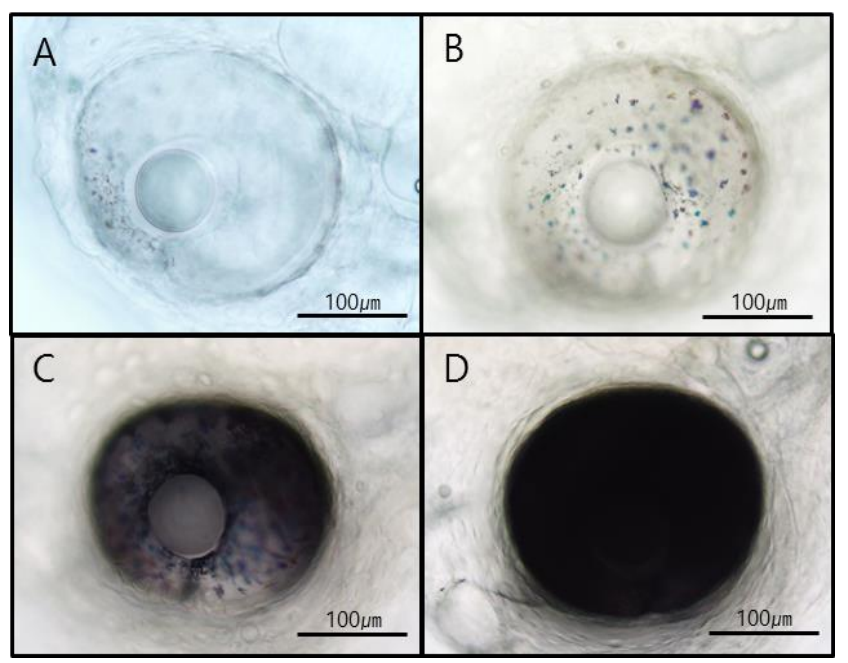

Fig. 2. Retinal pigmentation of early growth stage in red spotted grouper. A, 27 hah; B, 36 hah; $\mathrm{C}$ and D, 46 hah. hah, hours after hatching.

SWS2 was expressed in all brain areas, including the pituitary gland, and MWS was expressed in the forebrain and hindbrain. LWS was expressed in the hindbrain whereas rod was expressed in the forebrain. SWS2 was weakly expressed in gonads, which are peripheral tissues, and was expressed at similar levels in other tissues. MWS and rod were expressed strongly only in the retina. LWS was weakly expressed in the kidneys and spleen and strongly expressed in the retina.

\section{Expresion patterns of opsin genes according} growth stages

When real-time quantitative PCR was conducted on opsin genes, SWS2 expression started from 1 dah. The expression increased until 10 dah and then decreased thereafter (Fig. 5). MWS expression started on 3 dah and was the highest on 21 dah (Fig. 6). LWS expression started on 3 dah and was the highest (Fig. 7). Rod expression started on 2 dah and was the highest on 50 dah (Fig. 8). We confirmed that photoreceptors differentiated at different time points: on 21 dah for MWS, 3 dah for LWS, on 50 dah for rod. Moreover, regarding the degree of expression of the genes in each growth stage, the expression level of LWS opsin was much greater than those of other opsin genes.

\section{DISCUSSION}

Eyes play important roles for fish to find foods and to avoid predators (Cerri, 1983; Rodriguez \& Gisbert, 2001). Moreover, retinal differentiation in fish is closely related to metamorphosis, and rod differentiation during metamorphosiscan can also improve their vision (Rahman et al., 1979). The timing of retinal differentiation is speciesspecific. For Konosirus punctatus, a seawater fish species, lenses form at 5 dah (day after hatching), and retinal formation is complete at 9 dah (Park et al., 2006). According to a previous study, the eyes of Cynoglossus joyneri have no retinal pigmentation and the presence of photoreceptors could not be confirmed at hatching. However, the eyes were pigmented after the first feeding, and pure-cone retina 


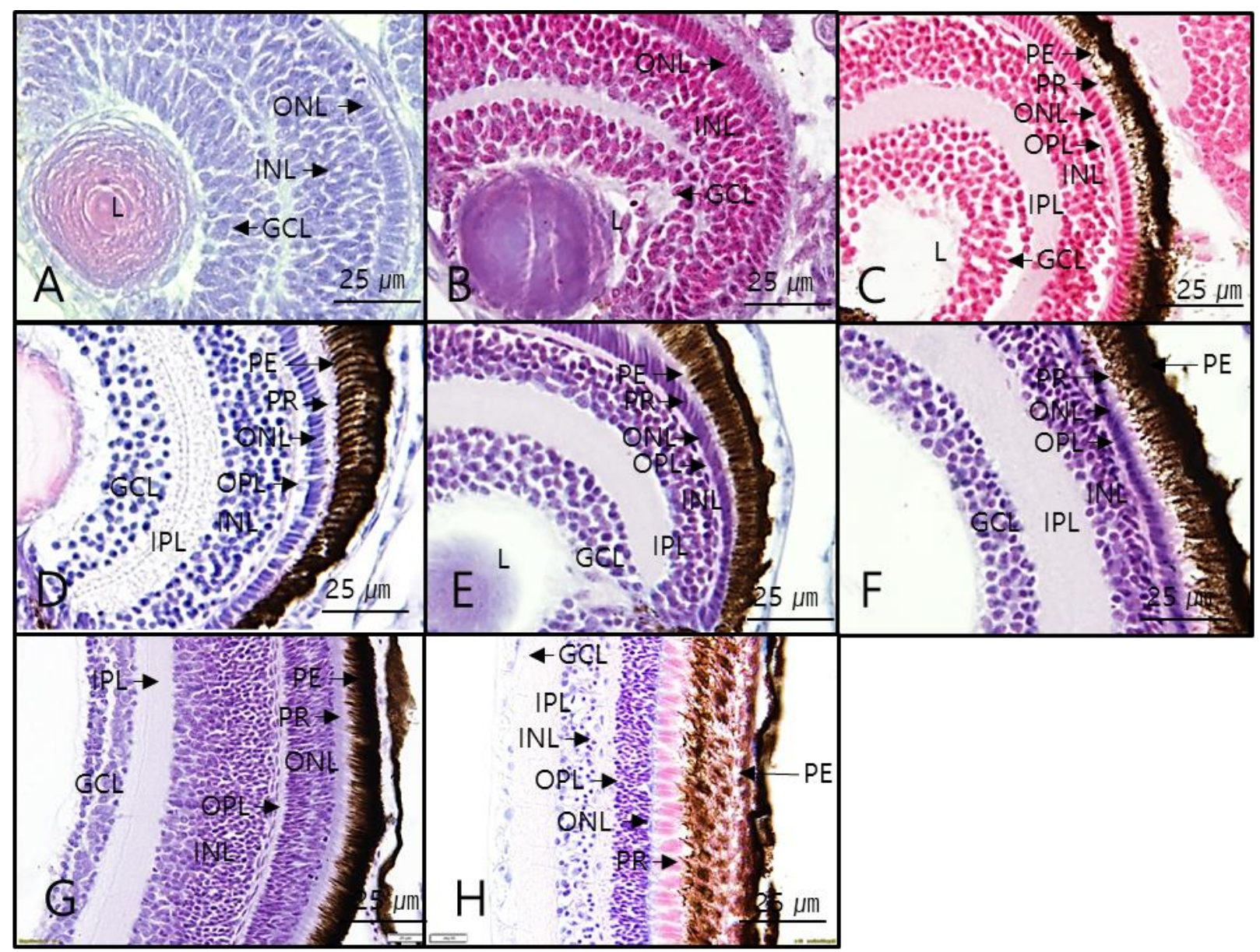

Fig. 3. Retinal development of early growth stage in red spotted grouper by HE stain. A, 2 dah; B, 3 dah; C, 4 dah; D, 5 dah; E, 10 dah; F, 21 dah; G, 50 dah; H, 12 months after hatching. The eye show the thick pigment epithelium (PE), photoreceptors (PR), outer nuclear layer (ONL), outer plexiform layer (OPL), inner nuclear layer (INL), inner plexiform layer (IPL), ganglion cell layer (GCL) and lens (L). dah, days after hatching; Unit, $\mu \mathrm{m}$.

formed soon; rod-like transformation followed early in metamorphosis (Sandy et al., 1980).

Upon investigation of the eye structure of red spotted grouper was investigated in this study through stereoscopic microscope images, yolk absorption was complete with black pigmentation of the eyes at 3 dah. Moreover, spines formed at 21 dah, and metamorphosis was complete at 50 dah. Upon investigation of layer differentiation of the retina was investigated through HE staining of hatched larvae sampled in each growth stage, ONL, INL, and GCL were differentiated at 2 dah and 3 dah although there was no pigmentation of the choroid membrane. The choroid membrane was pigmented at 4 dah, and retina was differentiated into PE, PR, ONL, OPL, INL, IPL, and GCL. Moreover, starting from the day 4 after hatching, the retinal layers were similar to those observed in 12-month-old red spotted grouper although the thickness of the layers were different; this suggests that differentiation of the eyes is almost complete. According to previous studies, pigmentation and differentiation of the eyes of Atlantic flat fish larvae prepare the fish to be able to hunt and digest preys (Kvenseth et al., 1996).

Three changes occur in the retina during metamorphosis of vertebrates. Photoreceptors change the visual pigments in the outer segment to alter their wavelength sensitivity, and new retinal cells are added and rearranged (Evans \& 
Table 2. Relative changes in thickness of retinal layers in each growth stage of red spotted grouper

\begin{tabular}{lccccccc}
\hline \hline & PE & ONL & OPL & INL & IPL & GCL & Total \\
\hline 2 dah $(\mathrm{n}=5)$ & & $6.2 \pm 0.3$ & & $23.0 \pm 1.3$ & & $16.7 \pm 1.1$ & $48.3 \pm 1.2$ \\
3 dah $(\mathrm{n}=4)$ & & $6.9 \pm 0.6$ & & $17.2 \pm 0.9$ & & $13.6 \pm 1.7$ & $40.8 \pm 1.5$ \\
4 dah $(\mathrm{n}=3)$ & $5.8 \pm 0.6$ & $4.7 \pm 0.4$ & & $11.0 \pm 0.8$ & & $12.2 \pm 1.9$ & $40.9 \pm 1.7$ \\
5 dah $(\mathrm{n}=2)$ & $15.0 \pm 0.3$ & $5.9 \pm 0.2$ & $3.0 \pm 1.0$ & $19.5 \pm 2.6$ & $12.7 \pm 1.7$ & $22.9 \pm 0.5$ & $85.1 \pm 6.1$ \\
10 dah $(\mathrm{n}=2)$ & $15.3 \pm 1.3$ & $4.8 \pm 0.4$ & $4.4 \pm 0.3$ & $17.8 \pm 6.3$ & $25.4 \pm 5.3$ & $18.3 \pm 2.3$ & $93.9 \pm 4.2$ \\
21 dah $(\mathrm{n}=2)$ & $20.8 \pm 2.0$ & $8.2 \pm 0.1$ & $3.4 \pm 0.5$ & $24.4 \pm 1.1$ & $26.0 \pm 4.6$ & $21.0 \pm 2.6$ & $113.0 \pm 13.6$ \\
50 dah $(\mathrm{n}=2)$ & $26.1 \pm 14.3$ & $25.4 \pm 5.6$ & $6.8 \pm 0.1$ & $48.6 \pm 1.1$ & $55.3 \pm 0.2$ & $14.2 \pm 2.6$ & $209.8 \pm 9.5$ \\
$12 \mathrm{M}(\mathrm{n}=2)$ & $38.4 \pm 3.6$ & $26.5 \pm 7.3$ & $11.3 \pm 0.9$ & $26.3 \pm 3.5$ & $30.9 \pm 5.6$ & $13.1 \pm 5.4$ & $185.2 \pm 43.2$ \\
\hline
\end{tabular}

PE, pigment epithelium; ONL, outer nuclear layer; OPL, outer plexiform layer; INL, inner nuclear layer; IPL, inner plexiform layer; GCL, ganglion cell layer; dah, day after hatching; Unit, $\mu \mathrm{m}$.

Table 3. Tissue expression in brain and peripheral tissue of red spotted grouper

\begin{tabular}{ccccccccccccccc}
\hline \hline & FB & MB & HB & Pt & Re & Gi & H & Ki & Sp & G & In & Mu & T \\
\hline SWS2 & + & + & + & + & + & + & + & + & + & + & + & + & + \\
MWS & + & - & + & - & ++ & - & + & + & + & - & - & - & - \\
LWS & - & - & + & - & ++ & - & - & + & + & - & - & - \\
Rod & + & - & - & - & ++ & - & - & - & - & - & - & - \\
\hline
\end{tabular}

FB, forebrain; MB, midbrain; HB, hindbrain, Pt, pituitaty; Re, retina; Gi, gill; H, heart; Ki, kidney; Sp, spleen; G, gonad; In, intestine; $\mathrm{Mu}$, muscles (including the lateral line); T, tongue; SWS2, short-wavelength sensitive opsin; MWS, middlewavelength sensitive opsin; LWS, long-wavelength sensitive opsin; ++, high expression; +, low expression; -, none expression.

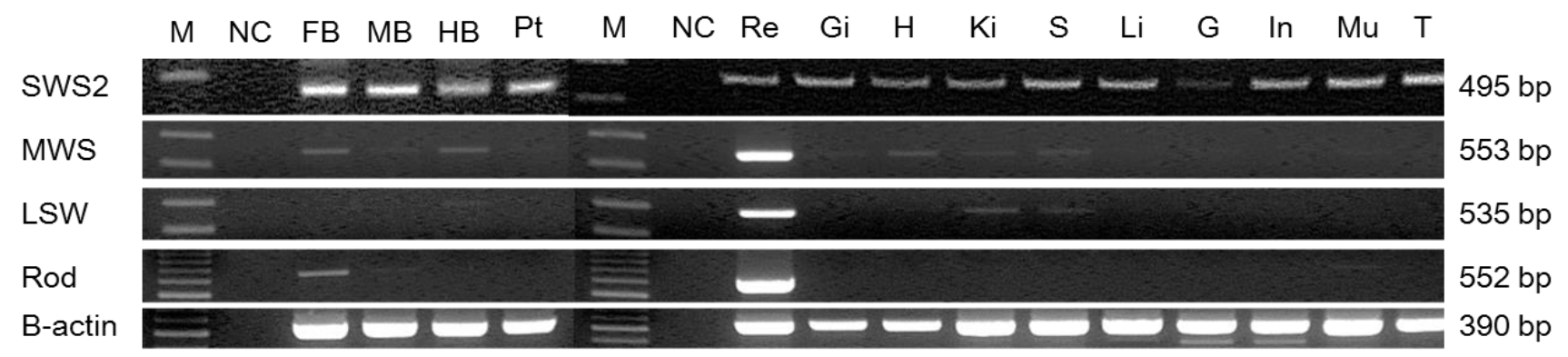

Fig. 4. Tissue specific expression of opsin genes in adult red spotted grouper. M, 100 bp DNA ladder marker; NC, negative control; FB, forebrain; MB, midbrain; HB, hindbrain, Pt, pituitary; Re, retina; Gi, gill; H, heart; Ki, kidney; Sp, spleen; G, gonad; In, intestine; Mu, muscles (including the lateral line); T, tongue; SWS2, short-wavelength sensitive opsin; MWS, middle-wavelength sensitive opsin; LWS, long-wavelength sensitive opsin. 


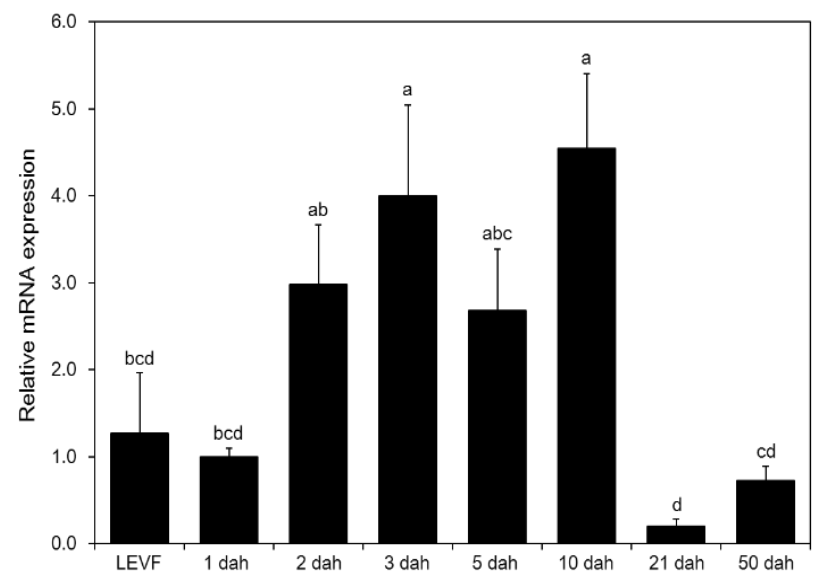

Fig. 5. SWS2 opsin mRNA expression in each growth stage of red spotted grouper by real-time quantitative PCR. The results are represented as means \pm SEM and different letters are significant $(p<0.05)$. LEVF, lens and ear vesicle formation stage of fertilized egg; dah, days after hatching; SWS2, shortwavelength sensitive opsin.

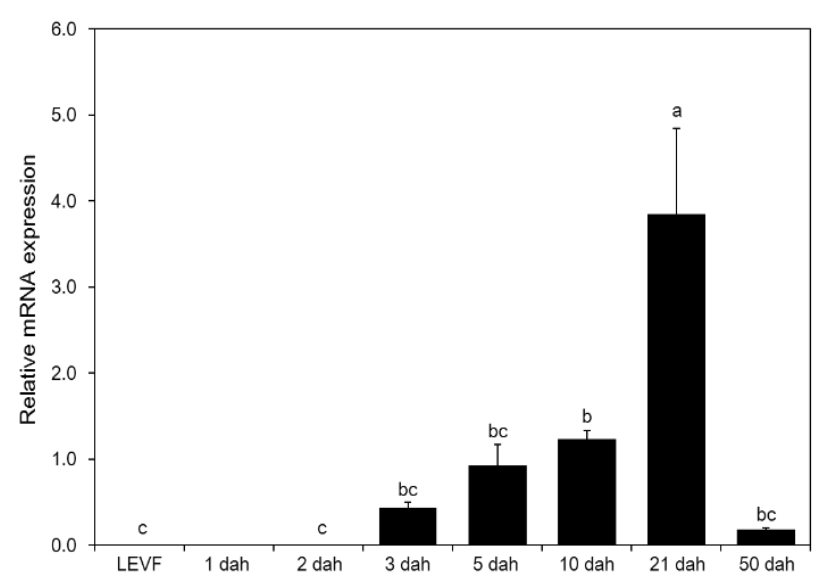

Fig. 6. MWS opsin mRNA expression in each growth stage of red spotted grouper by real-time quantitative PCR. The results are represented as means \pm SEM and different letters are significant $(p<0.05)$. LEVF, lens and ear vesicle formation stage of fertilized egg; dah, days after hatching; MWS, middle-wavelength sensitive opsin.

Fernald, 1990). In retinal development in Osteichthyes, cone photoreceptors develop first, followed by rod photoreceptors, and development timing of rods varies. According to the timing of rod photoreceptor differentiation, fish

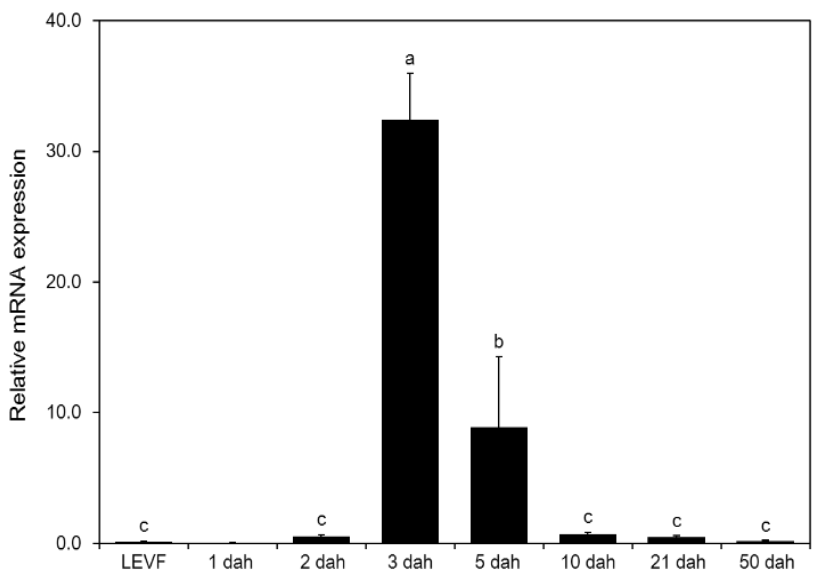

Fig. 7. LWS opsin mRNA expression in each growth stage red spotted grouper by real-time quantitative PCR. The results are represented as means \pm SEM and different letters are significant $(p<0.05)$. LEVF, lens and ear vesicle formation stage of fertilized egg; dah, days after hatching; LWS, longwavelength sensitive opsin.

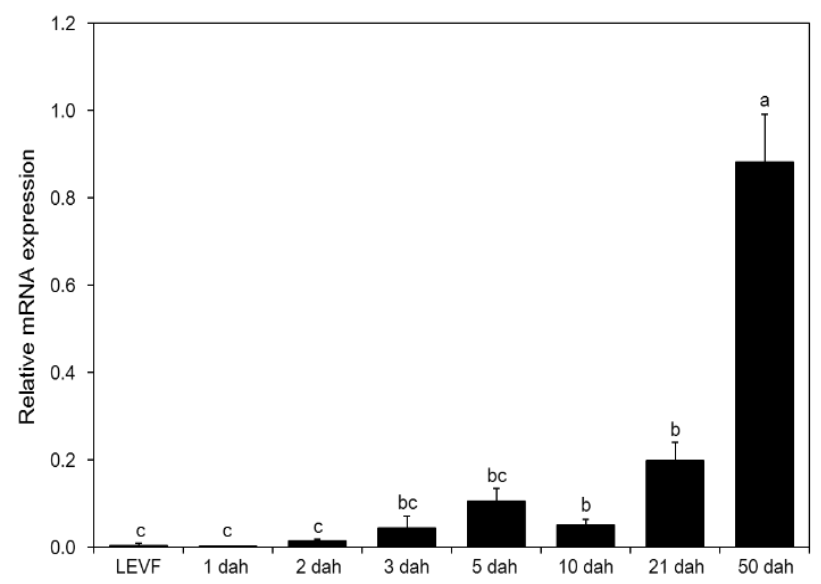

Fig. 8. Rod opsin mRNA expression in each growth stage of red spotted grouper by real-time quantitative PCR. The results are represented as means \pm SEM and different letters are significant $(p<0.05)$. LEVF, lens and ear vesicle formation stage of fertilized egg; dah, days after hatching.

retinal development is classified into indirect development, intermediate development, and direct development (Evans \& Fernald, 1990). Indirect development is present in most sea pelagic fish; cones differentiate at the time of hatching, and rods differentiate during metamorphosis. Intermediate 
development is often seen in Salmonidae, and cones differentiate at the time of hatching with rods differentiating before metamorphosis. Direct development is a characteristic seen in the fresh water fish and the territorial sea fish, and the cones and rods differentiate before hatching. Based on real-time qPCR, red spotted grouper seems to belong to the indirect development group whose cone photoreceptors develop at the time of hatching with the rods developing during metamorphosis. Moreover, when the first expressions of cone opsin genes and rod opsin were compared, the expression of rod opsin gene was noticeable at around the 50 dah.

In red spotted grouper larvae, all opsin genes were expressed at 3 dah, which corresponds to the completion of yolk absorption in hatched larvae. Atlantic flat fish (Hippoglossus hippoglossus) have slow development of the eyes, and the timing of eye development and that of organ differentiation and feeding match (Kvenseth et al., 1996); these characteristics are also seen in red spotted grouper. Previous studies on morphological development of red spotted grouper reported that their mouths open at around the days 4-5 after hatching with differentiation of digestive organs, including expansion of the internal diameter of the digestive tract. Our study, which investigated morphological development, retinal development, and opsin gene expression patterns in red spotted groupers, observed that retinal layer differentiation, first expression of opsin genes, and yolk absorption all happened around similar time points; this seems to be closely related to feeding behaviors of red spotted grouper.

In most fish species, including herring, (Sandy \& Blaxter, 1980), winter flounder, (Mader \& Cameron, 2004), and sockeye salmon (Flamarique \& Hawryshyn, 1996), cones differentiate before rods, and a similar pattern was also observed in red spotted grouper. Since opsin genes in red spotted grouper show maximum expression at different time points. In order to further investigate this, behavioral adaptation to farming environmental conditions should be analyzed in future studies.

\section{ACKNOWLEDGEMENTS}

This research was supported by Golden Seed Project, Ministry of Agriculture, Food and Rural Affairs (MAFRA), Ministry of Oceans and Fisheries (MOF), Rural Development Administration (RDA) and Korea Forest Service (KFS).

\section{REFERENCE}

Bozzano A, Pankhurst PM, Sabates A (2007) Early development of eye and retina in lanternfish larvae. Vis Neurosci 24:423-436.

Boeuf G, Le Bail PY (1999) Does light have an influence on fish growth? Aquaculture 177:129-152.

Carleton K (2009) Cichlid fish visual systems: Mechanisms of spectral tuning. Integr Zool 4: 74-86.

Cerri RD (1983) The effect of light intensity on predator and prey behaviour in cyprinid fish: factors that influence prey risk. Anim Behav 31:736-742.

Ellis EP, Watanabe WO, Ellis SC, Ginoza J, Moriwake A (1997) Effects of turbulence, salinity, and light intensity on hatching rate and survival of larval nassau grouper, Epinephelus striatus. J Appl Aquac 7:33-43.

Evans BI, Fernald RD (1990) Metamorphosis and fish vision. J Neurobiol 21:1037-1052.

Flamarique IN, Hawryshyn CW (1996) Retinal development and visual sensitivity of young pacific sockeye salmon (Oncorhynchus nerka). J Exp Biol 199:869-882.

Kim IS, Choi Y, Kim BJ (2001) Percoidei Fishes of Korea. Korea Research Institute of Bioscience and Biotechnology, Korea, p. 279.

Kvenseth AM, Pittman K, Helvik JV (1996) Eye development in Atlantic halibut (Hippoglossus hippoglossus): Differentiation and development of the retina from early yolk sac stages through metamorphosis. Can J Fish Aquat Sci 53:2524-2532. 
Mader MM, Cameron DA (2004) Photoreceptor differentiation during retinal development, growth, and regeneration in a metamorphic vertebrate. J Neurosci 24:1146311472 .

Mukai Y, Lim LS, Lu KC, Rashid MKA, Saad S (2012) Light intensity requirements for feeding behaviour by the brown-marbled grouper, Epinephelus fuscoguttatus. Sains Malays 41:1193-1196.

Park IS, Im SY, Seol DW, Lee JH, Hur JW, Jeong GS (2006) Early growth and development of eye in dotted gizzard shad, Konosirus punctatus. Dev Report 10:9396.

Park IS, Park HJ, Gil HW, Goo IB (2012) Early growth and characteristic of histological eye development in post parturition dark banded rockfish, Sebastes inermis. Dev Reprod 16:101-106.

Rahman H, Jeserich G, Zeutzius I (1979) Ontogeny of visual acuity of rainbow trout under normal conditions and light deprivation. Behavior 68:315-322.

Rodriguez A, Gisbert E (2001) Morphogenesis of the eye of Siberian sturgeon. J Fish Biol 59:1427-1429.

Sadovy Y (2001) Summary of regional survey of fry/fingerling supply for grouper mariculture in Southeast Asia. SPC Live Reef Fish Inf Bull 8:22-29.

Sakakura Y, Shiotani S, Chuda H, Hagiwara A (2006) Improvement of the survival in the seven-band grouper
Epinephelus septemfasciatus larvae by optimizing aeration and water inlet in the mass-scale rearing tank. Fish Sci 72:939-947.

Sandy JM, Blaxter JHS (1980) A study of retinal development in larval herring and sole. J Mar Biol Assoc UK 60:59-71.

Stenkamp DL (2015) Development of the vertebrate eye and retina. Prog Mol Biol Transl Sci 134:397-414.

Toledo JD, Caberoy NB, Quinitio GF, Choresca CH, Nakagawa H (2002) Effects of salinity, aeration and light intensity on oil globule absorption, feeding incidence, growth and survival of early-stage grouper Epinephelus coioides larvae. Fish Sci 68:478-483.

Villamizar N, Blanco-Vives B, Migaud H, Davie A, Carboni S, Sanchez-Vazquez FJ (2011) Effects of light during early larval development of some aquacultured teleosts: A review. Aquaculture 315:86-94.

Yamaoka K, Nanbu T, Miyagawa M, Isshiki T, Kusaka A (2000) Water surface tension-related deaths in prelarval red-spotted grouper. Aquaculture 189:165-176.

Yoseda K, Yamamoto K, Asami K, Chimura M, Hashimoto K, Kosaka S (2008) Influence of light intensity on feeding, growth, and early survival of leopard coral grouper (Plectropomus leopardus) larvae under mass-scale rearing conditions. Aquaculture 279:55-62. 